\title{
Sezgisel Bulanık WASPAS Yöntemi ve Depo Yeri Seçimi Problemi
}

\author{
Nihan TIRMIKÇIOĞLU ${ }^{1}$ \\ ${ }^{1}$ Kırklareli Üniversitesi, Fen Edebiyat Fakültesi, Matematik Bölümü, Kırklareli. \\ e-posta: ntirmik@klu.edu.tr ORCID ID: http://orcid.org/0000-0001-7646-5996 \\ Geliş Tarihi: 01.06.2021 Kabul Tarihi: 16.12.2021
}

\begin{tabular}{cl} 
& Öz \\
\cline { 2 - 3 } & Rekabetin yoğun olduğu günümüz iş dünyasında şirketler varlıklarını sürdürebilmek ve gelişebilmek için \\
& lojistik sistemlerinin optimizasyonu üzerinde yoğunlaşarak tedarik zinciri performansını güçlü tutmak \\
Anahtar kelimeler & durumundadırlar. Depolar, yerel veya küresel pazarda, bir tedarik zincir ağı için stratejik önemi büyük \\
Çok Kriterli Karar & noktalardır. Tedarik zincirleri birbirleriyle ürün teslim süresi ve genel ürün maliyetleri hususunda \\
Verme; & rekabet halindedirler. Depo konumu, tedarik zincir ağının verimliliğini ve hızını belirleyen en önemli \\
Bulanık Kümeler; & faktördür. Bu sebeple bir firma için depo yeri seçimi önemli bir yatırım kararıdır. Bu seçim aynı zamanda \\
Sezgisel Bulanık & nicel ve nitel kriterleri birlikte içeren bir çok kriterli karar verme problemi olarak değerlendirilebilir. \\
Kümeler; & Stratejik bir depo yeri seçiminde seçenekler karar vericiler tarafından belirlenen kriterler altında \\
Sezgisel Bulanık & değerlendirilirken kullanılan ifadelerin belirsizlik içerebilmesi nedeniyle problem, bulanık ortamda ele \\
WASPAS; & alınarak çözüme yönelik bir karar destek modeli önerilebilir. Çalışmamızda, yeni bir yaklaşım olarak, bir \\
SB-WASPAS & bulanık çok kriterli karar verme yöntemi olan bulanık WASPAS yöntemi sezgisel bulanık kümelerde \\
& geliştirilmiş olup bir tekstil firması için beş adet seçenek arasından en uygun depo yeri seçimi, karar \\
& vericilerin önerileri ve literatür taraması ile belirlenen beş kriter altında bir bulanık çok kriterli karar \\
& verme problemi olarak ele alınarak uygulanmıştır.
\end{tabular}

\section{Intuitionistic Fuzzy WASPAS and Warehouse Location Selection Problem}

\begin{tabular}{|c|c|}
\hline & Abstract \\
\hline $\begin{array}{c}\text { Keywords } \\
\text { Multi Criteria Decision } \\
\text { Making; } \\
\text { Fuzzy Sets; } \\
\text { Intuitionistic Fuzzy } \\
\text { Sets; } \\
\text { Intuitionistic Fuzzy } \\
\text { WASPAS; } \\
\text { IF WASPAS }\end{array}$ & $\begin{array}{l}\text { In today's business world, where the competition is intense, companies have to keep their supply chain } \\
\text { performance strong by focusing on the optimization of logistics systems in order to survive and develop. } \\
\text { Warehouses have a great strategic importance for a supply chain network in the local or global market. } \\
\text { Supply chains compete with each other over product delivery time and overall product costs. } \\
\text { Warehouse location is the most important factor determining the efficiency and speed of the supply } \\
\text { chain network. For this reason, warehouse location selection is an important investment decision for a } \\
\text { company. This selection can also be considered as a multi-criteria decision problem that includes both } \\
\text { quantitative and qualitative criteria. As the expressions used by the decision makers in the selection of } \\
\text { a strategic warehouse location to evaluate the criteria may contain uncertainty, the problem can be } \\
\text { considered in the fuzzy environment and a decision support model can be proposed to find the best } \\
\text { alternative. In our study, as a novel approach, the fuzzy WASPAS method which is a fuzzy multi-criteria } \\
\text { decision making method frequently used, is extended to intuitionistic fuzzy sets and applied to the } \\
\text { selection of the most appropriate warehouse location among five options for a textile company, } \\
\text { considering five criteria determined by decision-makers' suggestions and the literature review. }\end{array}$ \\
\hline
\end{tabular}




\section{Giriş}

Depo, hammadde ile satış öncesi dağılımdan önce ürünlerin tutuldukları büyük bir yapıdır. Genel uygulamada üretilen mallar, piyasadaki taleple doğru orantılı olarak satıcılara yönlendirilmeden önce üretim birimi tarafından depolara gönderilir. Bir firmanın, gelen talepleri sorunsuzca karşılayabilmek için ürünlerini muhafaza ettiği uygun bir depo alanı şarttır.

Depolama süreçleri tedarik zincirlerinde mal akış hızının artmasına önemli ölçüde katkıda bulunur. Her firma, ekonomik hedeflerini gerçekleştirmek için tedarik zincirini en verimli şekilde yönetmeye çalışır. Tedarik zinciri yönetimi, malların akışı, ne kadar üretileceği, hangi aşamalarda ne düzeyde planlama yapılacağı hususlarının yanı sıra her aşamada bu malların nasıl ve ne kadar depolanacağını da dikkate alır. Günümüzde depolama, etkili küresel tedarik zincir ağı için en önemli faktör haline gelmiştir. Esneklik, zamanında ya da daha kısa zamanda teslimat, kurumsal kârlılık gibi tedarik zincirinin farklı hedefleri depolama sayesinde kolaylıkla gerçekleşir. Bir deponun optimum konumu, düşük maliyet ve yüksek kâr prensipli tedarik zincirinin başarılı olmasını sağlar. $\mathrm{Bu}$ durumda, depo yeri için mevcut seçenekler arasından en uygun olanını belirlemek bir firma için büyük önem arz eder. Alan büyüklüğü ve yeterliliği, müşteri potansiyeli, tedarikçilere ulaşım, kilit pazarlarla bağlantılar, otoyol, tren ve havalimanlarına yakınlık, kalifiye iş gücü gibi faktörler yaygın olarak bir depo yeri araştırması için dikkate alınmaktadır. Yanlış bir kuruluş yeri seçim kararı ticari bir firma için ciddi kayıplara sebep olabilir. Bir depo, firmanın tedarik zincirinin verimliliğini artıran ve ürün sevkiyat sürecinde gecikmeye veya üretim maliyetinin artışına neden olmayan bir konumda olmalıdır. Deposunu talebin yoğun olduğu bölgeye yakın kuran firma müşterilerine zamanında ulaşır ve herhangi bir tedarik sıkıntısı yaşamaz.

Literatürde depo yeri seçimi ile ilgili pek çok çalışmaya rastlamak mümkündür. Çok kriterli karar verme problemi olarak ele alınıp karar verme yöntemleri kullanılarak ideal depo yerinin belirlendiği çalışmalar mevcuttur. Korpela ve
Tuominen (1996) tarafından yapılan çalışmada Analitik Hiyerarşi Süreci (AHP) yöntemi kullanılarak bir depo yeri seçimine yönelik çözüm önerilmiştir. Chen (2009), karar verme modelinde ticari potansiyel, ulaşım imkanları, sosyal faktörler ve arazi özellikleri kriterlerini belirleyerek Analitik Hiyerarşi Süreci (AHP) ve ağırlık merkezi yöntemini kullanarak bir karar destek modeli geliştirmiştir. Demirel vd. (2010), lojistik sektöründe bir depo yeri seçimi için maliyet, iş gücü, alt yapı, pazar özellikleri ve makro çevre kriterleri altında Choquet Integral Yöntemi'ni kullanmıştır. Singh vd. (2018), alt yapı, siyasi faktörler ve piyasa koşulları kriterlerini belirleyerek Bulanık Analitik Hiyerarşik Süreci ve bulanık TOPSIS yöntemleri ile en uygun depo yerini araştırmıştır. Jacyna-Golda vd. (2017), maliyet, ulaşım ve hammaddeye yakınlık kriterleriyle depo yeri seçim problemine genetik algoritmayı uygulamıştır. Ofoğlu vd. (2017) tarafından yapılan çalışmada afet durumunda bir depo yeri seçim modeli önerilmiş ve SAW, TOPSIS ve VIKOR yöntemleri aday depo yerlerinin arazi özellikleri ve ulaşım noktalarına uzaklıkları değerlendirilerek uygulanmıştır. Özbek ve Erol (2016), depo yeri seçimini bir çok kriterli karar verme problemi şeklinde ele alarak AHP, Basit Ağırlıklı Toplam, COPRAS ve MOORA yöntemlerini kullanmışlar ve elde edilen sonuçları karşılaştırmalı olarak analiz etmişlerdir. Aktepe ve Ersöz (2014) bir döküm fabrikası için ticari potansiyel ve maliyet kriterleri altında AHP, VIKOR ve MOORA yöntemlerini; Akyüz ve Soba (2013) tekstil sektöründe faaliyet gösteren bir fabrika için depo yeri konumunun fiziksel ve ekonomik özelliklerini değerlendirerek ELECTRE yöntemini, Kabadayı ve Esen(2021) bir 4.parti lojistik firma için (4PL) maliyet, konum özelliği ve ulaşım kolaylığı kriterleri ile Gri TOPSIS yöntemini kullanarak birer karar destek modeli önermişlerdir. Jayant (2015) bir üretim firması için bütünleşik VIKOR, TOPSIS ve Gri ilişkisel Analiz yöntemlerini kullanarak depo yeri seçim probleminde maliyet, stok kapasitesi, müşteri ve tedarikçilere uzaklık kriterlerini dikkate almıştır. Son dönemde yapılan çalışmalarda bulanık çok kriterli karar verme yöntemlerine de rastlamak mümkündür. Karmaker ve Saha(2015) hı, ulaşım imkanları, maliyetler, depo alan büyüklüğü, işgücü özellikleri ve üreticilere 
yakınlık kriterlerini göz önünde bulundurarak bulanık AHP ve bulanık TOPSIS yöntemlerini uygulamıştır. Sağnak (2020), perakende sektöründe depo yeri seçimi için modelde değerlendirme kriterlerini maliyet, fiziksel özellikler, güvenlik ve vergi politikası olarak belirlemiş ve bütünleşik AHPbulanık TODIM yöntemlerini kullanarak bir karar modeli önermiştir. Çalık(2020), Aralık Tip-2 Bulanık AHP ve Aralık Tip-2 Bulanık TOPSIS yöntemlerini depo yeri seçim karar modelinde kullanmış ve fiziksel özellikler, konum ve maliyet kriterlerini dikkate almıştır.

Bu çalışmada tekstil sektöründe faaliyet gösteren bir firma için depo yeri seçimi çok kriterli karar verme problemi olarak ele alınıp modellenmekte ve alternatifler arasında en uygun olanının belirlenmesine ilişkin bir karar destek modeli önerilmektedir. Depo yeri seçimi için her firmanın karar süreci finansal yapısı, pazarlama stratejisi, ürün çeşitliliği gibi faktörlere bağlı olarak değişiklik gösterebilir. Uzun vadeli bir yatırım kararı olması nedeniyle, amaç ve hedeflere uygun olarak belirlenen kriterler altında seçeneklerin titizlikle değerlendirilerek en uygun yerin belirlenmesi gerekir.

Karar destek modellerinde, karar vericilerin yaptıkları değerlendirmelerde kullanabilecekleri ifadeler biraz, daha, orta gibi belirsizlik gösteren niteleyiciler içerebileceğinden, klasik karar verme yöntemlerinde kullanılan sayısal ölçekler yetersiz kalabilir. Bulanık kümeler teorisi bu tür değerlendirmeleri matematiksel olarak anlamlandırabilmeye olanak sağlar. Bu çalışma, literatürde de çok kriterli karar verme problemi olarak geniş yer bulan depo yeri seçimi için yeni bir yaklaşım önermektedir. Bir çok kriterli karar verme tekniği olan WASPAS yöntemi ilk kez depo yeri seçimi problemi için sezgisel bulanık kümelerde geliştirilmekte ve bir karar destek modeli ortaya konmaktadır. Yapılan çalışmanın bilimsel katkısının yanında karar verme problemlerinde alternatif bir yöntem olarak tercih edilebileceği düşünülmektedir. Çalışmanın ikinci bölümünde bulanık kümelere farklı bir yaklaşım olan sezgisel bulanık kümelere değinilmektedir. Üçüncü bölümde yeni bir yaklaşım olarak sezgisel kümelerde geliştirilen bulanık WASPAS yöntemi sunulmaktadır. Dördüncü bölümde ise belirlenen kriterler altında beş aday depo yeri Sezgisel bulanık WASPAS yöntemi ile değerlendirilmektedir. Son bölümde elde edilen sonuçlar ve kullanılan yöntem yorumlanmaktadır.

\section{Sezgisel Bulanık Kümeler}

Günlük hayatta rastlanan problemlerde karşılaşılan belirsizlikler ve kişisel düşüncelerin kesin ifadeler içermemesi bu tür problemlerin çözümünü zorlaştırabilir. İlk olarak Zadeh tarafından ortaya konan bulanık küme teorisi klasik sayıların matematiksel olarak ifade etmekte yeterli olmayacağı dilsel ifadelerin sayısal olarak modellenmesine olanak sağlar. Bulanık küme teorisi kişisel yargılardan kaynaklanan dilsel belirsizliği bulanık sayılarla ifade eder (Chen 2000).

Bulanık küme, bir kümenin elemanını o kümeye aitlik derecesi ile tanımlayan karakteristik bir fonksiyondur. Bu fonksiyonun görüntü kümesi $[0,1]$ olup, bir elemanın görüntü değerinin 1 olması tam üyeliği belirtirken, 0 olması küme dışı olduğu anlamına gelir. Bu iki tamsayı dışında kalan değerler, elemanın kümeye aitlik derecesini bir başka deyişle üyelik derecesini belirler. Bir elemanın aitlik derecesi ile ait olmama derecesi toplamı 1'e eşittir (Zadeh 1965).

Belirsizliği modellemeyi esas alan klasik bulanık küme teorisi ilerleyen zamanlarda farklı yaklaşımlar ile geliştirilmeye başlanmıştır. Atanassov (1986) tarafından ortaya konan Sezgisel Bulanık Küme Teorisi'nde, klasik bulanık küme teorisinde olduğu gibi gene $[0,1]$ 'de değer alan aitlik derecesi tanımlanmaktadır. Ancak klasik bulanık küme teorisinden farklı olarak sezgisel bulanık kümelerde elamanların aitlik ve ait olmama dereceleri toplamı 1'e eşit olmayabilmektedir. Bu sebeple tereddütlük derecesi adı verilen üçüncü bir parametre daha tanımlanarak, sezgisel bulanık küme elemanlarının ilgili parametre değerleri 1'e eşitlenmektedir.

$X \neq \varnothing$ olmak üzere $X$ kümesinde $I$ sezgisel bulanık küme

$I=\left\{\left(x, \mu_{I}(x), \vartheta_{I}(x) \mid x \in X\right)\right\}$

şeklinde tanımlanır ( Atanassov 1986 ). $\mu_{I}(x) \epsilon[0,1]$ olup $x$ elemanın sezgisel bulanık kümeye aitlik 
derecesini, $\vartheta_{I}(x) \quad x$ elamanının sezgisel bulanık kümeye ait olmama derecesini gösterir. $\forall x \in X$ için

$0 \leq \mu_{I}(x)+\vartheta_{I}(x) \leq 1$

koşulu sağlanır. $\pi_{I}(x)$ tereddütlük derecesi olup

$\pi_{I}(x)=1-\mu_{I}(x)-\vartheta_{I}(x)$

şeklinde hesaplanır.

$I_{1}=\left(\mu_{1}, \vartheta_{1}\right)$ ve $I_{2}=\left(\mu_{2}, \vartheta_{2}\right)$ iki sezgisel bulanık sayı olsun. Bu iki bulanık sayı için şu cebirsel özellikler tanımlanır (Xu 2006) :

$I_{1} \oplus I_{2}=\left(\mu_{1}+\mu_{2}-\mu_{1} \mu_{2}, \vartheta_{1} \vartheta_{2}\right)$

$I_{1} \otimes I_{2}=\left(\mu_{1} \mu_{2}, \vartheta_{1}+\vartheta_{2}-\vartheta_{1} \vartheta_{2}\right)$

$\lambda I_{1}=\left(1-\left(1-\mu_{1}\right)^{\lambda}, \vartheta_{1}^{\lambda}\right), \lambda>0$

$I_{1}^{\lambda}=\left(\mu_{1}^{\lambda}, 1-\left(1-\vartheta_{1}\right)^{\lambda}\right), \quad \lambda>0$

$I_{1}$ ve $I_{2}$ bulanık sayıları için skor ve kesinlik fonksiyonları sırasıyla

$S\left(I_{1}\right)=\mu_{1}+\mu_{1}\left(1-\mu_{1}-\vartheta_{1}\right)$

$S\left(I_{2}\right)=\mu_{2}+\mu_{2}\left(1-\mu_{2}-\vartheta_{2}\right)$

$H\left(I_{1}\right)=\mu_{1}+\vartheta_{1}$

$H\left(I_{2}\right)=\mu_{2}+\vartheta_{2}$

olarak hesaplanır (Liu ve Wang 2007). Bu tanımlardan yola çıkarak iki sezgisel bulanık sayının büyüklük olarak karşılaştırılması

$S\left(I_{1}\right)<S\left(I_{2}\right)$ ise $I_{1}<I_{2}$

$S\left(I_{1}\right)>S\left(I_{2}\right)$ ise $I_{1}>I_{2}$

$S\left(I_{1}\right)=S\left(I_{2}\right), H\left(I_{1}\right)<H\left(I_{2}\right)$ ise $I_{1}<I_{2}$

$S\left(I_{1}\right)=S\left(I_{2}\right), H\left(I_{1}\right)>H\left(I_{2}\right)$ ise $I_{1}>I_{2}$

$S\left(I_{1}\right)=S\left(I_{2}\right), H\left(I_{1}\right)=H\left(I_{2}\right)$ ise $I_{1}=I_{2}$

şeklinde yapılır (Liu ve Wang 2007).

$I_{j}=\left(\mu_{I_{j}}, \vartheta_{I_{j}}\right)(j=1, \ldots, n)$ şeklinde verilen bir grup sezgisel bulanık sayı, önem dereceleri $\omega=$ $\left(\omega_{1}, \omega_{2}, \ldots, \omega_{n}\right)^{T}$ olmak üzere, sırasıyla sezgisel bulanık ağılıklı aritmetik ortalama $\left(I F W A_{\omega}\right)$ ve sezgisel bulanık ağırlıklı geometrik ortalama $\left(I F W G_{\omega}\right)$ operatörleri ile bir araya getirilebilir (Liu ve Wang 2007) :

$$
\operatorname{IFW} A_{\omega}\left(I_{1}, I_{2}, \ldots, I_{n}\right)=\left(\begin{array}{c}
1-\prod_{j=1}^{n}\left(1-\mu_{I_{j}}\right)^{\omega_{j}}, \\
\prod_{j=1}^{n}\left(\vartheta_{I_{j}}\right)^{\omega_{j}}
\end{array}\right)
$$

$I F W G_{\omega}\left(I_{1}, I_{2}, \ldots, I_{n}\right)=\left(\begin{array}{c}\prod_{j=1}^{n}\left(\mu_{I_{j}}\right)^{\omega_{j}}, \\ 1-\prod_{j=1}^{n}\left(1-\vartheta_{I_{j}}\right)^{\omega_{j}}\end{array}\right)$

\section{Sezgisel Bulanık WASPAS}

(Zavadkas vd. 2012) tarafından geliştirilen WASPAS (Weighted Aggregated Sum Product Assessment) yöntemi, WSM (Weighted Sum Model) Ağırlıklı Toplam Model ve WPM (Weighted Product Model) Ağırlıklı Çarpım Modeli'nin bir katsayıyla birleştirilmesi esasına dayanır. En yüksek tahmin doğruluğunu veren ağırlıklı toplamın da iyileştirilmesi hedeflenerek bu modeller bir katsayıyla birleştirilip doğrulukları test edilmiş ve önerilen yöntemin, seçim yapılacak alternatiflerin doğru ve güvenilir sıralanması için en uygun birleştirilmiş model olduğu ortaya konmuştur. WASPAS yöntemi yaygın kullanılan güvenilirliği yüksek bir karar verme yöntemi olup gerek klasik, gerek farklı tip bulanık kümelerde geliştirilmiş versiyonlarının çeşitli uygulamalarına literatürde rastlamak mümkündür. (Chakraborty ve Zavadskas 2014) robot üretim sürecinde, (Lashgari vd. 2014) dış kaynakların kullanım stratejilerinin değerlendirilmesinde, (Tayalı 2017) tedarikçi seçiminde, (Gavcar ve Organ 2020) online satış yapan seyahat acentalarının değerlendirilmesinde, (Arslanhan ve Tosun 2021) ulaşım modu seçim kararı için klasik WASPAS yöntemini uygulamışlardır. (Turskis vd. 2015) inşaat yeri seçimi için bulanık WASPAS yöntemini geliştirmişlerdir. (Keschawarz vd. 2016) aralıklı Tip-2 bulanık kümeleri kullanarak yeşil tedarikçilerin değerlendirilmesinde, (Nie vd.2017) nötrosofik bulanık kümeleri kullanarak güneş-rüzgar santral alanı seçiminde, (Gündoğdu ve Kahraman 2019) küresel bulanık kümelerde robot seçimi için WASPAS yöntemini kullanmışlardır.

Karar sürecinde belirlenen kriterler fayda yönlü ve maliyet yönü olarak nitelendirilebilir. Çok kriterli 
karar verme probleminde, değerlerinin en büyüklenmesi istenen fayda kriterleri ile en küçüklenmesi istenen maliyet kriterlerinin, geliştirilen modele katkılarını birlikte değerlendirebilme ve algoritma gereği duyarlılık analizi yaparak seçeneklerin sıralanmasındaki tutarlılığı da inceleyebilme özellikleri ile ön plana çıkan WASPAS yöntemi, çalışmaya konu olan ve karar kriterleri fayda yönlü ve maliyet yönlü niteliklerini taşıyan depo yeri seçim problemi için tercih edilmiş olup sezgisel bulanık kümelerde geliştirilmekte ve incelenmektedir.

Alternatiflerin kümesi $A L T=\left\{A L T_{1}, \ldots, A L T_{m}\right\}$ ve kriterlerin kümesi $K R=\left\{K R_{1}, \ldots, K R_{n}\right\}$ olmak üzere modele $l$ adet önem dereceleri birbirinden farklı karar vericiler dahil edilir. Karar vericilerin tecrübe ya da bilgi düzeyleri farklılık gösterebileceğinden önem dereceleri de birbirlerinden nicelik olarak az ya da fazla olabilir. $\lambda_{k} \geq 0(k=1,2, \ldots, l)$ olmak üzere $\lambda=\left\{\lambda_{1}, \ldots, \lambda_{l}\right\}$ karar vericilerin ağırlık vektörüdür ve $\sum_{k=1}^{l} \lambda_{k}=1$ 'dir. $\tilde{X}^{(k)}=\left(\tilde{x}_{i j}^{k}\right)_{m x n} k$. karar vericinin sezgisel bulanık değerlendirmelerinin yer aldığı karar matrisi olup $\tilde{x}_{i j}^{k}=\left(\mu_{i j}^{k}, \vartheta_{i j}^{k}, \pi_{i j}^{k}\right)$ sezgisel bulanık sayının tanımına göre $k$. karar vericiye göre $i$. alternatifin $j$. kriteri sağlama derecesi, sağlamama derecesi ve tereddütlük derecesini gösterir. $\tilde{X}=\left(\tilde{x}_{i j}\right)_{m x n}$ ise tüm karar vericilerin değerlendirilmelerinin birleştirildiği karar matrisidir.

Geliştirilen yöntemin adımları aşağıdaki verilen adımlarla sıralanmaktadır:

Adım 1. Karar verme modelinde, değerlendirme için kullanılacak olan dilsel değişkenler ile bu değişkenlere karşııık gelen sezgisel bulanık sayı değerleri belirlenir.

Adım 2. Karar vericilerin önem değerleri değerlendirilerek sezgisel bulanık sayı olarak ifade edilir ve her karar vericinin karar modelindeki ağırlığı hesaplanır.

$L_{k}=\left(\mu_{k}, \vartheta_{k}, \pi_{k}\right)$ k.karar vericinin önem derecesini gösteren bir sezgisel bulanık sayı olmak üzere k.karar vericinin ağırlığı, $\lambda_{k} \geq 0(k=1, \ldots, l)$ olmak üzere: $\lambda_{k}=\frac{\left(\mu_{k}+\pi_{k}\left(\frac{\mu_{k}}{\mu_{k}+\vartheta_{k}}\right)\right)}{\sum_{k=1}^{l}\left(\mu_{k}+\pi_{k}\left(\frac{\mu_{k}}{\mu_{k}+\vartheta_{k}}\right)\right)}$

şeklinde hesaplanır.

Adım 3. Karar verme modelinin kriterleri karar vericiler tarafından dilsel değişkenler ve sezgisel bulanık karşııkları ile değerlendirilir.

Çizelge 1. Kriterlerin Karar Vericiler Tarafından Değerlendirilmesi

\begin{tabular}{ccccc}
\hline & $\mathbf{K} \mathbf{V}_{\mathbf{1}}$ & $\mathbf{K} \mathbf{V}_{\mathbf{2}}$ & $\ldots$ & $\mathbf{K V}_{\mathbf{k}}$ \\
\hline $\mathbf{K R}_{\mathbf{1}}$ & $\left(\mu_{11}, \vartheta_{11}, \pi_{11}\right)$ & $\left(\mu_{12}, \vartheta_{12}, \pi_{12}\right)$ & $\ldots$ & $\left(\mu_{1 k}, \vartheta_{1 k}, \pi_{1 k}\right)$ \\
$\mathbf{K R}_{2}$ & $\left(\mu_{21}, \vartheta_{21}, \pi_{21}\right)$ & $\left(\mu_{22}, \vartheta_{22}, \pi_{22}\right)$ & $\ldots$ & $\left(\mu_{2 k}, \vartheta_{2 k}, \pi_{2 k}\right)$ \\
$\vdots$ & $\vdots$ & $\vdots$ & $\vdots$ & $\vdots$ \\
$\mathbf{K R}_{\mathbf{n}}$ & $\left(\mu_{n 1}, \vartheta_{n 1}, \pi_{n 1}\right)$ & $\left(\mu_{n 2}, \vartheta_{n 2}, \pi_{n 2}\right)$ & $\ldots$ & $\left(\mu_{n k}, \vartheta_{n k}, \pi_{n k}\right)$
\end{tabular}

Adım 4. Karar vericilerin önem ağırlıkları $\left(\lambda_{1}, \lambda_{2}, \ldots, \lambda_{k}\right)$ dikkate alınarak yaptıkları kriter değerlendirmeleri sezgisel bulanık ağırlıklı aritmetik ortalama operatörü $\left(I F W A_{\lambda}\right)$ ile birleştirilir

$$
I F W A_{\lambda}\left(I_{1}, I_{2}, \ldots, I_{n}\right)=\left(\begin{array}{c}
1-\prod_{j=1}^{n}\left(1-\mu_{I_{j}}\right)^{\lambda_{j}} \\
\prod_{j=1}^{n}\left(\vartheta_{I_{j}}\right)^{\lambda_{j}}
\end{array}\right)
$$

Adım 5. Birleştirilmiş sezgisel bulanık kriter değerleri, sezgisel bulanık sayılar için tanımlanan skor fonksiyon ile durulaştırıır :

$\omega_{j}=\mu_{j}+\mu_{j}\left(1-\mu_{j}-\vartheta_{j}\right)(j=1, \ldots, n)$

Adım 6. Bulunan kriter skor değerleri normalleştirilerek kriter ağılıkları hesaplanır :

$\bar{\omega}_{j}=\frac{\omega_{j}}{\sum_{j=1}^{n} \omega_{j}}$

$j=1, \ldots, n ; 0<\bar{\omega}_{j}<1 ; \sum_{j=1}^{n} \bar{\omega}_{j}=1$

Adım 7. Alternatifler belirlenen kriterler altında her bir karar verici tarafından değerlendirilir ve yapılan değerlendirmeler biraraya getirilerek birleştirilmiş karar matrisi $\tilde{X}$ oluşturulur. 
$\tilde{x}_{i j}^{k}=\left(\mu_{i j}^{k}, \vartheta_{i j}^{k}, \pi_{i j}^{k}\right)(k=1, \ldots, l) k$. karar vericinin j.kriter altında $i$. alternatif için sezgisel bulanık değerlendirmesi olmak üzere

$$
\tilde{X}^{(k)}=\left(\tilde{x}_{i j}^{k}\right)_{m x n}=\left(\begin{array}{cccc}
\tilde{x}_{11}^{k} & \tilde{x}_{12}^{k} & \ldots & \tilde{x}_{1 n}^{k} \\
\tilde{x}_{21}^{k} & \tilde{x}_{22}^{k} & \ldots & \tilde{x}_{2 n}^{k} \\
\ldots & \ldots & \ldots & \ldots \\
\tilde{x}_{m 1}^{k} & \tilde{x}_{m 2}^{k} & \ldots & \tilde{x}_{m n}^{k}
\end{array}\right)
$$

$\widetilde{X}=\left(\tilde{x}_{i j}\right)_{m x n}=\left(\begin{array}{cccc}\tilde{x}_{11} & \tilde{x}_{12} & \ldots & \tilde{x}_{1 n} \\ \tilde{x}_{21} & \tilde{x}_{22} & \ldots & \tilde{x}_{2 n} \\ \ldots & \ldots & \ldots & \ldots \\ \tilde{x}_{m 1} & \tilde{x}_{m 2} & \ldots & \tilde{x}_{m n}\end{array}\right)$

$\tilde{x}_{i j}=\left(1-\prod_{k=1}^{l}\left(1-\mu_{\tilde{x}_{i j}^{k}}\right)^{\lambda_{k}}, \prod_{k=1}^{l}\left(\vartheta_{\tilde{x}_{i j}^{k}}\right)^{\lambda_{k}}\right)(25)$

şeklindedir.

Adım 8. Birleştirilmiş karar matrisi normalleştirilerek $\tilde{R}=\left(\tilde{r}_{i j}\right)_{m x n}$ birleştirilmiş normalleştirilmiş karar matrisi oluşturulur (Liang,2020). $F$ ve $M$ sırasıyla fayda ve maliyet kriterleri olmak üzere normalleştirilmiş karar matrisinin elemanları :

$\tilde{r}_{i j}=\left\{\begin{array}{l}\left(\mu_{\tilde{x}_{i j}}, \vartheta_{\tilde{x}_{i j}}\right), j \epsilon F \\ \left(\vartheta_{\tilde{x}_{i j}}, \mu_{\tilde{x}_{i j}}\right), j \in M\end{array}\right.$

şeklinde oluşturulur.

Adım 9. Alternatiflerin ağırlıklı toplam modele göre nispi önem değerleri elde edilir :

$\widetilde{Q}_{i}^{(1)}=\sum_{j=1}^{n} \tilde{r}_{i j} * \bar{\omega}_{j}$

(27) denklemi iki aşamalı olarak hesaplanır. Çarpma aşaması (6) tanımı kullanılarak yapılır:

$\tilde{r}_{i j} * \bar{\omega}_{j}=\left(1-\left(1-\mu_{\tilde{r}_{i j}}\right)^{\bar{\omega}_{j}},\left(\vartheta_{\tilde{r}_{i j}}\right)^{\bar{\omega}_{j}}\right)$

İkinci aşamada her toplam terimi (4) tanımı kullanılarak hesaplanır. Örneğin ilk iki terim için :

$$
\begin{aligned}
\tilde{r}_{i 1 \bar{\omega}}+\tilde{r}_{i 2 \bar{\omega}}= & \left(\mu_{\tilde{r}_{i 1 \bar{\omega}}}+\mu_{\tilde{r}_{i 2 \bar{\omega}}}-\right. \\
& \left.\mu_{\tilde{r}_{i 1 \bar{\omega}}} \mu_{\tilde{r}_{i 2 \bar{\omega}}}, \vartheta_{\tilde{r}_{i 1 \bar{\omega}}} \vartheta_{\tilde{r}_{i 2 \bar{\omega}}}\right)
\end{aligned}
$$

Adım 10. Ağırlıklı çarpım modeli kullanılarak (VPM) aşamalı olarak alternatiflerin nisbi önemleri hesaplanır.

$\tilde{Q}_{i}^{(2)}=\prod_{j=1}^{n} \tilde{r}_{i j}{ }^{\bar{\omega}_{j}}$
(30) denklemi iki hesaplanır. Öncelikle (7) tanımı kullanılarak üs alma işlemi yapılır:

$\tilde{r}_{i j}^{\bar{\omega}_{j}}=\left(\mu_{\tilde{r}_{i j}}^{\bar{\omega}_{j}}, 1-\left(1-\vartheta_{\tilde{r}_{i j}}\right)^{\bar{\omega}_{j}}\right)$

Sonrasında (5) tanımı kullanılarak her çarpım terimi hesaplanır. Örneğin ilk iki terim için :

$\tilde{r}_{i 1}^{\bar{\omega}_{1}} \otimes \tilde{r}_{i 2}^{\bar{\omega}_{2}}=\left(\mu_{\tilde{r}_{i 1}}^{\bar{\omega}_{1}} \mu_{\tilde{r}_{i 2}}^{\bar{\omega}_{2}}, \vartheta_{\tilde{r}_{i 1}}^{\bar{\omega}_{1}}+\vartheta_{\tilde{r}_{i 2}}^{\bar{\omega}_{2}}-\vartheta_{\tilde{r}_{i 1}}^{\bar{\omega}_{1}} \vartheta_{\tilde{r}_{i 2}}^{\bar{\omega}_{2}}\right)$

Adım 11. Alternatiflerin her iki modele göre hesaplanan nisbi önemleri, aynı zamanda bir karar verme duyarlılık katsayısı olan $\lambda$ bütünleştirme katsayısı $(0 \leq \lambda \leq 1)$ ile biraraya getirilerek çarpma özelliği (6) kullanılarak toplam nisbi önem değerleri, hesaplanır :

$\tilde{Q}_{i}=\lambda \tilde{Q}_{i}^{(1)}+(1-\lambda) \tilde{Q}_{i}^{(2)}$

Burada, $\lambda$ değerinin seçimi, karar vericiye bırakılmaktadır. Tanım olarak, $\lambda=0$ alındığında karar modeli ağırlıklı toplam modele, $\lambda=1$ ağırlıklı çarpım modeline dönüşmektedir.

Adım 12. Hesaplanan nisbi değerler, skor fonksiyon değerleri hesaplanarak büyükten küçüğe doğru sıralanır. En yüksek skor değeri olan alternatif ideal seçimdir. Skor değerlerinin eşit olması durumunda kesinlik fonksiyon değerleri hesaplanarak sıralama yapılır.

Adım 13. Alternatiflerin sıralamalarını incelemek amacıyla $\lambda$ katsayısına farklı değerler atanarak duyarlılık analizi gerçekleştirilir.

Adım 14. (34) denklemiyle optimal $\lambda$ bulunarak (33) denklemiyle bulunan sıralamaların güvenilirliği test edilir :

$\lambda=\frac{\sum_{i=1}^{m} Q_{i}^{(2)}}{\sum_{i=1}^{m} Q_{i}^{(1)}+\sum_{i=1}^{m} Q_{i}^{(2)}}$ 


\section{Uygulama}

Üretim yeri Trakya bölgesinde bulunan bir firma pazarlama ve lojistik faaliyetlerini büyütmek için İstanbul'da bir depo kurmaya karar vermiştir. Müşterilerine tedarik sürecinde herhangi bir problem yaşamadan kısa sürede ulaşmayı hedefleyen ve aynı zamanda kurumsal kârlılığını da dikkate alan firma için, ürün teslimde gecikmeye ve üretim maliyetlerinde artışa da sebep vermeyecek uygun bir depo yeri seçimi büyük önem taşımaktadır. Bunun için Ümraniye $\left(A L T_{1}\right)$, Bayrampaşa $\left(A L T_{2}\right)$, Kurtköy $\left(A L T_{3}\right)$, Maslak $\left(A L T_{4}\right)$ ve Hadımköy $\left(A L T_{5}\right)$ olmak üzere 5 adet aday depo yeri belirlemiştir. Karar vericiler olarak firmanın genel müdürü, perakende satış müdürü ve lojistik sektöründe tecrübesi yüksek olan bir endüstri mühendisi görev almıştır. Gerek literatür taraması gerekse firma ile yapılan görüşmeler sonucu beş tane kriter belirlenmiştir :

Ulaşım Kolaylığı $\left(\boldsymbol{K} \boldsymbol{R}_{\mathbf{1}}\right)$ : Depodaki malların talep edilen yerlere hızlı ve zamanında ulaştırılması firma için oldukça önemlidir ve müşteriler için de tercih edilme sebebidir. $\mathrm{Bu}$ nedenle depo yerinin seçiminde otoyol, havaalanı, demiryolu, liman gibi taşıma yollarına yakın olması firma tarafından dikkate alınan bir faktör olmuştur.

Satış Hacmi $\left(\boldsymbol{K} \boldsymbol{R}_{\mathbf{2}}\right)$ : Deponun satışların ve müşteri potansiyelinin yüksek olduğu bir bölgeye kurulması hem müşterilerin dilediği zaman hizmet alabilmesi hem de potansiyel müşterilere yakın olabilmek adına önemli bir avantajdır. Ayrıca işletmenin taşıma maliyetlerini önemli ölçüde azaltır.

Rakip firma sayısı $\left(\boldsymbol{K} \boldsymbol{R}_{\mathbf{3}}\right)$ : Firma müşteri portföyünü zenginleştirmek hedefindedir. Potansiyel müşterilere yakın olabilmek ve pazardan pay almak için rakiplerinin yoğun olarak bulunduğu bölgelerde var olma düşüncesindedir. Bu nedenle rakip firmaların sayısı değerlendirilecek bir diğer seçim kriteri olarak belirlenmiştir.

Nitelikli iş gücü $\left(\boldsymbol{K} \boldsymbol{R}_{\mathbf{4}}\right)$ : Bir işletmenin başarılı olmasına etki eden faktörlerden biri de bünyesindeki insan kaynağının niteliğidir. Potansiyel nitelikli iş gücü, karar almada bir kriter olarak uygulanacak modele eklenmiştir.
Depo Kiralama Maliyeti $\left(\boldsymbol{K} \boldsymbol{R}_{\mathbf{5}}\right)$ : İşletmeler kâr etme amacıyla kurulmuş iktisadi kuruluşlardır ve faaliyetlerinde maliyet kalemlerinin düşük olmasını hedefler. Bu nedenle, seçeneklerin bulunduğu bölgelerde kiralama maliyeti değerlendirmede dikkate alınması gereken bir kriter olarak öne çıkmıştır.

Kriterler belirlendikten sonra bulanık karar destek modelini uygulanması aşamasına geçilmiştir :

Adım 1. Öncelikle karar vericilerin kriterleri ve alternatifleri değerlendirecekleri dilsel değişkenler ve sezgisel bulanık sayı karşılıkları belirlenmiş ve Çizelge 2 ve Çizelge 3 'te sunulmuştur (Yıldırım 2019):

Çizelge 2. Karar vericilerin önem düzeyi ve kriterlerin ağırlığını belirlemede kullanılan değerlendirme ölçeği

\begin{tabular}{ll}
\hline Dilsel Değişkenler & $\begin{array}{l}\text { Sezgisel Bulanık } \\
\text { Sayı }\end{array}$ \\
\hline Çok Yüksek (ÇY) & $(0.9,0.1,0.0)$ \\
Yüksek(Y) & $(0.75,0.2,0.05)$ \\
Orta (O) & $(0.5,0.45,0.05)$ \\
Düşük(D) & $(0.35,0.6,0.05)$ \\
Çok Düşük(ÇD) & $(0.1,0.9,0.0)$ \\
\hline
\end{tabular}

Çizelge 3. Alternatifleri Değerlendirmede Kullanılan Değerlendirme Ölçeği

\begin{tabular}{ll}
\hline Dilsel Değişkenler & $\begin{array}{l}\text { Sezgisel Bulanık } \\
\text { Sayı }\end{array}$ \\
\hline Çok İyi & $(0.75,0.1,0.15)$ \\
İyi & $(0.6,0.25,0.15)$ \\
Orta & $(0.5,0.5,0.0)$ \\
Kötü & $(0.25,0.6,0.15)$ \\
Çok Kötü & $(0.1,0.75,0.15)$
\end{tabular}

Adım 2. Karar vericilerin önem düzeyleri atanarak ağırlıkları (19) denklemiyle hesaplanmış ve Çizelge 4 'te verilmiştir : 
Çizelge 4. Karar Vericilerin Önem Düzey ve Ağırlıkları

\begin{tabular}{lccc}
\hline & $\boldsymbol{K} \boldsymbol{V}_{\mathbf{1}}$ & $\boldsymbol{K} \boldsymbol{V}_{\mathbf{2}}$ & $\boldsymbol{K} \boldsymbol{V}_{\mathbf{3}}$ \\
\hline Önem & ÇY & ÇY & $\mathrm{Y}$ \\
Ăğırlık & 0.348 & 0.348 & 0.305
\end{tabular}

Örneğin üçüncü karar vericinin karar destek modelindeki ağırlığı :

$$
\lambda_{3}=\frac{0.75+0.05\left(\frac{0.75}{0.75+0.20)}\right.}{\left(\begin{array}{c}
0.9+0\left(\frac{0.9}{0.9+0.1}\right)+0.9+0 .\left(\frac{0.9}{0.9+0.1}\right)+ \\
0.75+0.05\left(\frac{0.75}{0.75+0.20}\right)
\end{array}\right)}
$$

$=0.305$

olarak hesaplanmıştır.

Adım 3. Karar vericiler tarafından kriterler değerlendirilmiş ve yapılan değerlendirmeler Çizelge 5'te sunulmuştur :

Çizelge 5. Kriterlerin Karar Vericiler Tarafından Değerlendirilmesi

\begin{tabular}{cccc}
\hline Karar Vericiler & $K V_{1}$ & $K V_{2}$ & $K V_{3}$ \\
Önem dereceleri & $\mathbf{0 . 3 4 8}$ & $\mathbf{0 . 3 4 8}$ & $\mathbf{0 . 3 0 5}$ \\
\hline$K R_{1}$ & ÇY & ÇY & $\mathrm{Y}$ \\
$K R_{2}$ & ÇY & ÇY & ÇY \\
$K R_{3}$ & $\mathrm{Y}$ & $\mathrm{Y}$ & $\mathrm{O}$ \\
$K R_{4}$ & $\mathrm{O}$ & $\mathrm{O}$ & $\mathrm{Y}$ \\
$K R_{5}$ & $\mathrm{Y}$ & $\mathrm{Y}$ & $\mathrm{Y}$ \\
\hline
\end{tabular}

Adım 4. Kriter değerlendirmeleri karar vericilerin önem düzeyleri de dikkate alınarak (20) denklemiyle birleştirilmiş ve kriterlerin sezgisel bulanık ağırlık değerleri elde edilmiştir.

Örneğin birinci kriterin $\left(K R_{1}\right)$ sezgisel bulanık ağırlık değeri için karar vericiler tarafından yapılan sezgisel bulanık değerlendirmeler şu şekilde hesaplanır :

$$
\begin{aligned}
\left(\mu_{K R 1}, \vartheta_{K R 1}\right)= & I F W A_{\lambda}\left(K V_{1}, K V_{2}, \ldots, K V_{n}\right) \\
= & \left(\begin{array}{c}
1-\prod_{j=1}^{n}\left(1-\mu_{K V_{j}}\right)^{\lambda_{j}}, \\
\prod_{j=1}^{n}\left(\vartheta_{K V_{j}}\right)^{\lambda_{j}}
\end{array}\right)
\end{aligned}
$$

$=\left(\left(1-\left\{(1-0.9)^{0.348} *(1-0.9)^{0.348} *(1-\right.\right.\right.$

$\left.\left.\left.0.75)^{0.302}\right\}\right),(0.1)^{0.348} *(0.1)^{0.348} *(0.2)^{0.302}\right)$

$=(0.868,0.124))$

Tereddütlük Derecesi ise

$\pi_{K R 1}=1-(0.868+0.124)=0.009$

olarak hesaplanmıştır. Diğer kriterlerin ağırlıkları aynı şekilde hesaplanmış ve Çizelge 6'da sunulmuştur :

Çizelge 6 . Kriterlerin Sezgisel Bulanık Ağırlıkları

$\begin{array}{lc}K R_{1} & (0.868,0.124,0.009) \\ K R_{2} & (0.90,0.10,0.0) \\ K R_{3} & (0.691,0.264,0.044) \\ K R_{4} & (0.595,0.378,0.027) \\ K R_{5} & (0.75,0.2,0.05)\end{array}$

Adım 5. Sezgisel bulanık kriter ağırlıkları (21) denklemi ile durulaştırılmış ve (22) denklemi ile normalleştirilerek kriter ağırlıkları elde edilmiştir. Örneğin birinci kriterin $\left(K R_{1}\right)$ ağırlık skor değeri :

$$
0.868+0.868(1-0.868-0.124)=0.875
$$

olup normalleştirilmiş ağırlık değeri

$$
\frac{0.875}{3.896}=0.225
$$

olarak hesaplanmıştır. Tüm kriterlerin skor değerleri ve normalleştirilmiş skor değerleri Çizelge 7'de verilmiştir :

Çizelge 7 . Kriterlerin Skor Değerleri ve Normalleştirilmiş Edilmiş Ağırlık Değerleri

\begin{tabular}{ccc}
\hline & $\begin{array}{c}\text { Skor } \\
\text { değerleri }\end{array}$ & $\begin{array}{c}\text { Normalleştirilmiş skor } \\
\text { değerleri }\end{array}$ \\
\hline $\boldsymbol{K R}_{\mathbf{1}}$ & 0.875 & 0.225 \\
$\boldsymbol{K} \boldsymbol{R}_{\mathbf{2}}$ & 0.900 & 0.231 \\
$\boldsymbol{K} \boldsymbol{R}_{\mathbf{3}}$ & 0.722 & 0.185 \\
$\boldsymbol{K} \boldsymbol{R}_{\mathbf{4}}$ & 0.611 & 0.157 \\
$\boldsymbol{K} \boldsymbol{R}_{\mathbf{5}}$ & 0.788 & 0.202 \\
$\mathbf{T o p l a m}$ & 3.896 & 1.000 \\
\hline
\end{tabular}


Böylece karar destek modelindeki kriterlerin ağırlıklar $\{0.225,0.231,0.185,0.157,0.202\}$ olarak belirlenmiştir. Buradan karar vericiler için en önemli kriterin en yüksek ağırlık değerini taşıyan satış hacmi kriteri olduğu görülmektedir.

Adım 6. Yöntemin bu aşamasında alternatifler karar vericiler tarafından değerlendirilmektedir :

Çizelge 8 . Alternatiflerin Değerlendirilmesi

\begin{tabular}{|c|c|c|c|c|}
\hline Kriterler & Alternatifler & $K V_{1}$ & $K V_{1}$ & $K V_{1}$ \\
\hline \multirow{5}{*}{$K R_{1}$} & $A L T_{1}$ & $\bar{i}$ & i & 0 \\
\hline & $A L T_{2}$ & çi & çi & çi \\
\hline & $A L T_{3}$ & 0 & 0 & $\mathrm{~K}$ \\
\hline & $A L T_{4}$ & i & $\mathrm{i}$ & $\mathrm{i}$ \\
\hline & $A L T_{5}$ & $\mathrm{i}$ & 0 & $\mathrm{i}$ \\
\hline \multirow{6}{*}{$K R_{2}$} & $A L T_{1}$ & $i$ & i & $i$ \\
\hline & $A L T_{2}$ & $\mathrm{i}$ & çi & çi \\
\hline & $A L T_{3}$ & çi & çi & $\mathrm{i}$ \\
\hline & $A L T_{4}$ & i & $\mathrm{i}$ & 0 \\
\hline & $A L T_{5}$ & $\mathrm{i}$ & $\mathrm{i}$ & $\mathrm{i}$ \\
\hline & $A L T_{1}$ & $i$ & i & i \\
\hline \multirow{4}{*}{$K R_{3}$} & $A L T_{2}$ & çi & i & $\mathrm{i}$ \\
\hline & $A L T_{3}$ & 0 & K & K \\
\hline & $A L T_{4}$ & K & 0 & $\mathrm{O}$ \\
\hline & $A L T_{5}$ & i & i & $\mathrm{i}$ \\
\hline \multirow{5}{*}{$K R_{4}$} & $A L T_{1}$ & çi & i & $\bar{i}$ \\
\hline & $A L T_{2}$ & çi & çi & çi \\
\hline & $A L T_{3}$ & K & K & K \\
\hline & $A L T_{4}$ & i & $\mathrm{i}$ & çi \\
\hline & $A L T_{5}$ & $\mathrm{O}$ & 0 & $\mathrm{O}$ \\
\hline \multirow{5}{*}{$K R_{5}$} & $A L T_{1}$ & $i$ & $i$ & $i$ \\
\hline & $A L T_{2}$ & çi & i & $\mathrm{i}$ \\
\hline & $A L T_{3}$ & $\mathrm{~K}$ & 0 & K \\
\hline & $A L T_{4}$ & i & 0 & 0 \\
\hline & $A L T_{5}$ & çi & çi & çi \\
\hline
\end{tabular}

Yapılan değerlendirmeler sezgisel bulanık sayılara çevrilmiş ve karar vericilerin önem değerleri dikkate alınarak (25) denklemiyle biraraya getirilmiştir. Birleştirilmiş karar matris Çizelge 9'da sunulmaktadır:

Çizelge 9 . Birleştirilmiş Karar Matrisi

\begin{tabular}{llllll}
\hline & \multicolumn{1}{c}{$\boldsymbol{K} \boldsymbol{R}_{\mathbf{1}}$} & \multicolumn{1}{c}{$\boldsymbol{K R}_{\mathbf{2}}$} & \multicolumn{1}{c}{$\boldsymbol{K R}_{\mathbf{3}}$} & \multicolumn{1}{c}{$\boldsymbol{K R}_{\mathbf{4}}$} & \multicolumn{1}{c}{$\boldsymbol{K R}_{\mathbf{5}}$} \\
\hline $\boldsymbol{A L T}_{1}$ & $(0.57,0.3$ & $(0.6,0.25$ & $(0.6,0.25$ & $(0.66,0.8$ & $(0.6,0.25$ \\
& $1,0.12)$ & $, 0.15)$ & $, 0.15)$ & $2,0.16)$ & $0.15)$ \\
$\boldsymbol{A L T}_{:}$ & $(0.75,0.1$ & $(0.71,0.1$ & $(0.66,0.1$ & $(0.75,0.1$ & $(0.66,0.1$ \\
& $0,0.15)$ & $4,0.16)$ & $8,0.16)$ & $0,0.15)$ & $8,0.16)$ \\
$\boldsymbol{A L T}_{:}$ & $(0.43,0.5$ & $(0.71,0.1$ & $(0.35,0.5$ & $(0.5,0.5$, & $(0.35,0.5$ \\
& $3,0.04)$ & $3,0.16)$ & $6,0.09)$ & 0 & $6,0.09)$ \\
$\boldsymbol{A L T}_{\llcorner}$ & $(0.6,0.25$ & $(0.57,0.3$ & $(0.42,0.5$ & $(0.06,0.1$ & $(0.5,0.5$ \\
& $, 0.15)$ & $1,0.12)$ & $3,0.04)$ & $9,0.16)$ & $0)$ \\
$\boldsymbol{A L T}_{:}$ & $(0.57,0.3$ & $(0.6,0.25$ & $(0.6,0.25$ & $(0.5,0.5$, & $(0.75,0.1$ \\
& $2,0.14)$ & $, 0.15)$ & $, 0.15)$ & $0)$ & $, 0.15)$
\end{tabular}

Adım 7. Çalışmamızda ilk dört kriter fayda yönlü olup, beşinci kriter maliyet yönlü kriter olduğundan birleştirilmiş karar matrisi (26) eşitliği kullanılarak normalleştirilmiş ve Çizelge $10^{\prime}$ da verilmiştir:

Çizelge 10 . Normalleştirilmiş Karar Matrisi

\begin{tabular}{llllll}
\hline & \multicolumn{1}{c}{$\boldsymbol{K} \boldsymbol{R}_{\mathbf{1}}$} & \multicolumn{1}{c}{$\boldsymbol{K} \boldsymbol{R}_{\mathbf{2}}$} & \multicolumn{1}{c}{$\boldsymbol{K} \boldsymbol{R}_{\mathbf{3}}$} & \multicolumn{1}{c}{$\boldsymbol{K \boldsymbol { R } _ { \mathbf { 4 } }}$} & \multicolumn{1}{c}{$\boldsymbol{K \boldsymbol { R } _ { \mathbf { 5 } }}$} \\
\hline $\boldsymbol{A L T} \boldsymbol{T}_{1}$ & $(0.57,0.3$ & $(0.6,0.25$, & $(0.6,0.25$, & $(0.66,0.8$ & $(0.25,0.6$, \\
& $1,0.12)$ & $0.15)$ & $0.15)$ & $2,0.16)$ & $0.15)$ \\
$\boldsymbol{A L T}_{2}$ & $(0.75,0.1$ & $(0.71,0.1$ & $(0.66,0.1$ & $(0.75,0.1$ & $(0.18,0.6$ \\
& $0,0.15)$ & $4,0.16)$ & $8,0.16)$ & $0,0.15)$ & $6,0.16)$ \\
$\boldsymbol{A L T}_{3}$ & $(0.43,0.5$ & $(0.71,0.1$ & $(0.35,0.5$ & $(0.5,0.5,0$ & $(0.56,0.3$ \\
& $3,0.04)$ & $3,0.16)$ & $6,0.09)$ & ) & $5,0.09)$ \\
$\boldsymbol{A L T}_{4}$ & $(0.6,0.25$, & $(0.57,0.3$ & $(0.42,0.5$ & $(0.06,0.1$ & $(0.5,0.5,0$ \\
& $0.15)$ & $1,0.12)$ & $3,0.04)$ & $9,0.16)$ & ) \\
$\boldsymbol{A L T}_{\mathbf{5}}$ & $(0.57,0.3$ & $(0.6,0.25$, & $(0.6,0.25$, & $(0.5,0.5,0$ & $(0.1,0.75$ \\
& $2,0.14)$ & $0.15)$ & $0.15)$ & ) & $, 0.15)$ \\
\hline
\end{tabular}

Adım 8. Normalleştirilmiş matris, Adım 5'te hesaplanan kriter ağırlıkları ile ağılıklı toplam modele göre (28)-(29) denklemleriyle ağırlıklandırılarak alternatiflerin $Q_{i}^{(1)}$ nisbi önem değerleri ; ağırlıklı çarpım modeline göre (31)-(32) denklemleriyle ağırlıklandıılarak alternatiflerin $Q_{i}^{(2)}$ nisbi önem değerleri elde edilmiş ve Çizelge 11 'de sunulmuştur: 
Çizelge 11 . Alternatiflerin $Q_{i}^{(1)}$ ve $Q_{i}^{(2)}$ nisbi önem değerleri

\begin{tabular}{ccc}
\hline & $\boldsymbol{Q}_{i}^{(\mathbf{1})}$ & $\boldsymbol{Q}_{i}^{(2)}$ \\
\hline $\boldsymbol{A L T}_{\mathbf{1}}$ & $(0.550,0.298,0.152)$ & $(0.603,0.254,0.144)$ \\
$\boldsymbol{A L T}_{\mathbf{2}}$ & $(0.651,0.176,0.173)$ & $(0.704,0.141,0.155)$ \\
$\boldsymbol{A L T}_{3}$ & $(0.537,0.354,0.109)$ & $(0.409,0.468,0.123)$ \\
$\boldsymbol{A L T}_{\mathbf{4}}$ & $(0.538,0.337,0.125)$ & $(0.513,0.346,0.141)$ \\
$\boldsymbol{A L T}_{\mathbf{5}}$ & $(0.503,0.367,0.129)$ & $(0.562,0.285,0.153)$ \\
\hline
\end{tabular}

Adım 9. Duyarlılık katsayısı, yöntemi oluşturan ağırlıklı toplam ve ağırlıklı çarpım modellerinin eşit katkıda bulunduğu kabul edilerek $\lambda=0.5$ alınmış ve (33) denklemiyle alternatiflerin toplam sezgisel bulanık nisbi önem değerleri $\left(Q_{i}\right)$ hesaplanarak Çizelge 12 'de verilmiştir :

Çizelge 12 . Alternatiflerin toplam sezgisel bulanık $Q_{i}$ değerleri

\begin{tabular}{cccc}
\hline & $\lambda Q_{i}^{(1)}$ & $(1-\lambda) Q_{i}^{(2)}$ & $Q_{i}$ \\
\hline $\boldsymbol{A L T}_{\mathbf{1}}$ & $(0.33,0.55,0.13)$ & $(0.3,0.50,0.13)$ & $(0.58,0.28,0.15)$ \\
$\boldsymbol{A L T}_{\mathbf{2}}$ & $(0.41,0.2,0.17)$ & $(0.46,0.38,0.17)$ & $(0.68,0.16,0.16)$ \\
$\boldsymbol{A L T}_{3}$ & $(0.32,0.59,0.09)$ & $(0.23,0.68,0.08)$ & $(0.48,0.41,0.12)$ \\
$\boldsymbol{A L T}_{\mathbf{4}}$ & $(0.32,0.58,0.09)$ & $(0.30,0.59,0.11)$ & $(0.53,0.34,0.13)$ \\
$\boldsymbol{A L T}_{\mathbf{5}}$ & $(0.29,0.61,0.09)$ & $(0.34,0.53,0.13)$ & $(0.53,0.32,0.14)$ \\
\hline
\end{tabular}

Adım 10. Alternatiflerin (21) denklemi ile durulaştırılan $Q_{i}$ nisbi önem değerleri Çizelge 13 'de sunulmuştur :

Çizelge 13. Alternatiflerin $Q_{i}$ değerleri

\begin{tabular}{ccc}
\hline Alternatifler & $\boldsymbol{Q}_{i}^{(1)}$ & $\boldsymbol{Q}_{i}^{(2)}$ \\
\hline $\boldsymbol{A L T} \boldsymbol{T}_{1}$ & 0.634 & 0.689 \\
$\boldsymbol{A L T}_{2}$ & 0.763 & 0.813 \\
$\boldsymbol{A L T}_{3}$ & 0.596 & 0.459 \\
$\boldsymbol{A L T}_{\mathbf{4}}$ & 0.605 & 0.585 \\
$\boldsymbol{A L T}_{\mathbf{5}}$ & 0.568 & 0.648 \\
\hline
\end{tabular}

Yönteme göre alternatiflerin nisbi önem değerleri büyükten küçüğe $A L T_{2}>A L T_{1}>A L T_{5}>A L T_{4}>$ $A L T_{3}$ olarak sıralanmış olup buna göre en yüksek $Q_{i}$ değerine sahip ikinci alternatif olan Bayrampaşa
$\left(A L T_{2}\right)$ karar destek modelinde en iyi alternatif olarak önerilmektedir. Bunu Ümraniye, Hadımköy, Maslak ve Kurtköy takip etmektedir.

Adım 11. Bu aşamada duyarlılık analizi yapılmış ve farklı $\lambda$ değerleri için alternatiflerin Çizelge 14 'te verilen nisbi önem değerleri $\left(Q_{i}\right)$ hesaplanmıştır:

Çizelge 14. Farklı $\lambda$ değerleri için $Q$ değerleri

\begin{tabular}{cccccc}
\hline $\boldsymbol{\lambda}$ & $\boldsymbol{A L T}_{\mathbf{1}}$ & $\boldsymbol{A L T}_{\mathbf{2}}$ & $\boldsymbol{A L T}_{\mathbf{3}}$ & $\boldsymbol{A L T}_{\mathbf{4}}$ & $\boldsymbol{A L T}_{\mathbf{5}}$ \\
\hline $\mathbf{0}$ & 0.689 & 0.813 & 0.459 & 0.585 & 0.648 \\
$\mathbf{0 . 1}$ & 0.684 & 0.809 & 0.475 & 0.587 & 0.640 \\
$\mathbf{0 . 2}$ & 0.679 & 0.804 & 0.90 & 0.590 & 0.633 \\
$\mathbf{0 . 3}$ & 0.674 & 0.799 & 0.504 & 0.591 & 0.625 \\
$\mathbf{0 . 4}$ & 0.668 & 0.795 & 0.519 & 0.593 & 0.617 \\
$\mathbf{0 . 5}$ & 0.662 & 0.790 & 0.532 & 0.595 & 0.609 \\
$\mathbf{0 . 6}$ & 0.657 & 0.785 & 0.546 & 0.597 & 0.602 \\
$\mathbf{0 . 7}$ & 0.651 & 0.779 & 0.559 & 0.599 & 0.594 \\
$\mathbf{0 . 8}$ & 0.646 & 0.774 & 0.572 & 0.610 & 0.585 \\
$\mathbf{0 . 9}$ & 0.640 & 0.769 & 0.584 & 0.603 & 0.577 \\
$\mathbf{1}$ & 0.634 & 0.763 & 0.596 & 0.605 & 0.568 \\
\hline
\end{tabular}

Yapılan duyarlılık analizi neticesinde, tüm $\lambda$ değerleri için alternatiflerin nisbi değerlerine $\left(Q_{i}\right)$ göre sıralamalarının aynı kaldığı görülmektedir.

Adım 12. Çizelge $11^{\prime}$ de verilen alternatiflerin sezgisel bulanık $Q_{i}^{(1)}$ ve $Q_{i}^{(2)}$ değerleri (21) denklemi ile durulaştırılarak Çizelge 15'te verilmiştir:

Çizelge 15. Alternatiflerin durulaştırılmış $Q_{i}^{(1)}$ ve $Q_{i}^{(2)}$ değerleri

\begin{tabular}{cc}
\hline Alternatifler & $\boldsymbol{Q}_{\boldsymbol{i}}$ \\
\hline $\boldsymbol{A L T} \boldsymbol{T}_{1}$ & 0.663 \\
$\boldsymbol{A L T} \boldsymbol{T}_{\mathbf{2}}$ & 0.790 \\
$\boldsymbol{A L T}_{3}$ & 0.532 \\
$\boldsymbol{A L T}_{\mathbf{4}}$ & 0.595 \\
$\boldsymbol{A L T}_{\mathbf{5}}$ & 0.610 \\
\hline
\end{tabular}

Örneğin birinci alternatif olan Ümraniye $\left(A L T_{1}\right)$ için durulaştırılmış $Q^{(1)}$ değeri :

$$
\begin{aligned}
\mathrm{Q}_{\mathrm{ALT}_{1}}^{(1)}=0.550 & +0.50 *(1-0.550-0.298) \\
& =0.634
\end{aligned}
$$


olarak hesaplanmıştır. Bu değerler ile, özel olarak her alternatif için (34) denklemi yardımıyla optimal $\lambda$ katsayıları belirlenerek alternatiflerin nisbi değerleri hesaplanmış ve karar destek modeli için önerilen sıralamanın doğruluğu test edilmiştir(Arslanhan ve Tosun 2021). Örneğin birinci alternatif $\left(A L T_{1}\right)$ için optimal $\lambda$ değeri

$$
\lambda=\frac{0.689}{0.689+0.634}=0.521
$$

olup nisbi değeri :

$$
\begin{gathered}
Q_{A L T_{1}}=0.521 * 0634+(1-0,521) * 0,689 \\
=0.662
\end{gathered}
$$

şeklindedir. Alternatiflerin optimal $\lambda$ değerleri ve nisbi önem değerlerinin yer aldığı Çizelge 16 incelendiğinde $A L T_{2}>A L T_{1}>A L T_{5}>A L T_{4}>A L T_{3}$ sıralamasının değiş̧mediği dolayısıyla geliştirilen yöntemin ve yapılan hesaplamaların tutarlı olduğu görülmektedir.

Çizelge 16. Alternatiflerin optimal $\lambda$ değerleri ve göreli nisbi önem değerleri

\begin{tabular}{ccc}
\hline & Optimal $\lambda$ & $\boldsymbol{Q}_{\boldsymbol{i}}$ \\
\hline $\boldsymbol{A L T} \boldsymbol{T}_{1}$ & 0.521 & 0.662 \\
$\boldsymbol{A L T}_{2}$ & 0.516 & 0.787 \\
$\boldsymbol{A L T} \boldsymbol{T}_{3}$ & 0.435 & 0,519 \\
$\boldsymbol{A L T}_{4}$ & 0.492 & 0.595 \\
$\boldsymbol{A L T}_{5}$ & 0.533 & 0,605 \\
\end{tabular}

\section{Tartışma ve Sonuç}

Günümüz dünyasında küreselleşme ve ilerleyen teknolojiyle birlikte rekabetin arttığı koşullarda, işletmelerin varlıklarını sürdürebilmeleri ve büyümeleri için birçok faktörü dikkate alması zorunludur. Bilhassa üretim sektöründe faaliyet gösteren işletmelerin sağlam bir tedarik zinciri yönetimine ihtiyaç duyduğu açıktır. Bu noktada ürün depolama tedarik zinciri yönetiminde en etkili faktördür. En düşük maliyet ve en yüksek kar prensibiyle faaliyet gösteren iktisadi işletmeler için uygun depo yeri seçimi bilhassa uzun vadeli bir planlama yapılarak alınması gereken oldukça önemli bir ekonomik ve stratejik karardır. Yanlış bir seçim işletmeyi geriye dönülemeyecek büyüklükte bir maddi zararla karşı karşıya bırakabilir.

Bu çalışmada tekstil sektöründe faaliyet gösteren bir firmaya uygun depo yer seçimi için bir karar destek modeli geliştirilmiştir. Belirlenen kriterler altında en iyi seçeneğin belirlenmesi gerektiğinden çalışma bir çok kriterli karar verme problemi olarak ele alınmıştır. Literatür çalışmasıyla birlikte çalışmaya katılan karar vericilerin belirlediği kriterler değerlendirilerek modeldeki ağırlık değerleri hesaplanmış, bu kriterler altında alternatifler değerlendirilmiş ve geliştirilen karar verme modelinin adımlarına uygun olarak veriler işlenerek en uygun seçenek belirlenmiştir. Yapılan kriter değerlendirmelerinde en önemli kriterin depo yeri alternatiflerinin bulundukları bölgelerde yapılan toplam satışlar olduğu gözlemlenmiş ve bunu yakın bir değerle ulaşım olanakları kriterinin takip ettiği görülmüştür. Beş alternatif arasından en uygun seçeneğin Bayrampaşa olduğu belirlenmiştir. Optimal alternatifin yüksek ağırlıklı kriterler arasında da baskın olarak olumlu değerlendirildiği göze çarpmaktadır.

Bir karar verme modelinde, değerlendirme yapan karar vericilerin alanında yeterince bilgi birikimi ve iş tecrübesi olması esastır. Bununla birlikte kişisel değerlendirmelerin de kimi zaman kesinlik içermeyebileceği, biraz, orta ya da arada gibi niteleyiciler kullanabileceği olasıdır. Bu tip belirsizlik içeren değerlendirmelerin matematiksel olarak ifade edilebilmesi için bulanık kümeler kullanılmaktadır. Ait ve ait olmama derecesini esas alan bulanık kümeler, Atanassov tarafından geliştirilerek, tereddütlük derecesi kavramı da eklenmiştir. Böylece klasik bulanık kümelere göre belirsizliği daha esnek ifade edebilme avantajı da ortaya çıkmıştır. Çalışmamızda, bir çok kriterli karar verme yöntemi olarak yaygın kullanılan ve ağırlıklı toplam ve ağılıklı çarpım modellerini bütünleştirerek ideal bir çözüm sunan WASPAS yöntemi, yeni bir yaklaşım olarak sezgisel bulanık kümelerde ortaya konmuş ve geliştirilen karar destek modelinde uygulanmıştır. Modelde, farklı 
bütünleştirme katsayı değerleri için ve yanı sıra her alternatif için ayrı ayrı önerilen optimal bütünleştirme katsayıları ile alternatiflerin nisbi önem dereceleri hesaplanmıştır. Yapılan sıralamalarda herhangi bir değişikliğin olmaması gerek sezgisel bulanık kümelerde kurulan modelin gerekse yapılan hesaplamaların tutarlılığını ortaya koymuştur.

İlerleyen çalışmalarda, depo yeri seçimi gibi çok kriterli karar verme problemi niteliği taşıyan tüm uygulamalar için mevcut diğer karar verme yöntemleri yeni bir yaklaşım olarak sezgisel bulanık kümelerde geliştirilebilir ve bütünleşik olarak da birlikte yorumlanabilir.

\section{Kaynaklar}

Aktepe, A. and Ersöz, S., 2014. AHP, VIKOR ve MOORA yöntemlerinin depo yeri seçim problemine uygulanması. Endüstri Mühendisliği Dergisi, 25(1) , 215.

Akyüz, Y. and Soba, M., 2013. ELECTRE yöntemiyle tekstil sektöründe optimal kuruluş yeri seçimi: Uşak ili örneği. Uluslararası Yönetim iktisat ve Iş̧letme Dergisi, 9(19), 185-198

Arslanhan, H. and Tosun, Ö., 2021. Ulaştırma modu seçimi probleminin bütünleşik en iyi-en kötü ve WASPAS yöntemleriyle çözülmesi. Pamukkale Üniversitesi Mühendislik Bilimleri Dergisi, 27(1), 1323.

Atanassov, K.T., 1986. Intuitionistic fuzzy sets. Fuzzy Sets Systems, 20, 87-96.

Chakraborty, S., Zavadskas, E.K., 2014. Applications of WASPAS method in manufacturing decision making. Informatica, 25(1), 1-20.

Chen, C., 2009. A decision model of field depot location based on the centrobaric method and Analytic Hierarchy Process (AHP). International Journal of Business and Management, 4(7), 71-75.

Chen,C.T., 2000. A fuzzy approach to select the location of the distribution center, Fuzzy Sets and Systems, 114, 1-9.
Çalık, A., 2020. Depo yeri seçimi için Aralık Tip-2 Bulanık ÇKKV tabanlı hibrit bir yaklaşım. Manas Sosyal Araştırmalar Dergisi, 9(1),101-114.

Demirel,T., Demirel, N. Ç. and Kahraman, C., 2010. Multicriteria warehouse location selection using Choquet integral. Expert Systems with Applications, 37(5), 3943-3952.

Gavcar, C.T. and Organ, A., 2020. Evaluation of travel agencies who sell online with AHP-GRA and AHPWASPAS. Business and Management Studies : An International Journal , 8(1), 731-753.

Gündoğdu, F.K. and Kahraman, C., 2019. Extension of Fuzzy WASPAS with spherical fuzzy sets. Informatica, 30(2), 269-292.

Jacyna-Golda, I.,Izdebski, M. and Podviezko, A., 2017. Assessment of efficiency of assignment of vehicles to tasks in supply chains: a case study of a municipal company. Transport, 32(3), 243-251.

Jayant, A., 2015. Use of Grey Relational Analysis in solving multiple attribute decision making problem: a case study of warehouse location selection. Advances in Industrial Engineering and Management, 4(2), 2157-164.

Kabadayı,N. and Esen,Ç.T.E., 2021. Gri İlişkisel Temelli TOPSIS yöntemi ile depo yeri seçimi. Anemon Muş Alparslan Üniversitesi Sosyal Bilimler Dergisi, 9(1), 169-184.

Karmaker, C.L. and Saha, M., 2015. Optimization of warehouse location through fuzzy multi-criteria decision making methods. Decision Science Letters, 4 , 315-334

Keshavarz Ghorabaee, M., Zavadskas, E.K., Amiri, M., Esmaeili, A., 2016. Multi-criteria evaluation of green suppliers using an extended WASPAS method with interval type-2 fuzzy sets. Journal of Cleaner Production, 137, 213-229.

Korpela, J. and Tuominen, M., 1996. A decision support system for strategic issues management of logistics. International Journal of Production Economics, 4647(1), 605-620. 
Lashgari, S., Antucheviciene, J., Delavari, A., Kheirkhah, O., 2014. Using QSPM and WASPAS methods for determining outsourcing strategies. Journal of Business Economics and Management, 15(4), 729743.

Liang, Y., 2020. An EDAS Method for Multiple Attribute Group Decision Making under intuitionistic fuzzy environment and its Application for evaluating green building energy-saving design projects. Symmmetry, 12, 484, 1-12.

Liu H.W and Wang, G.J., 2007. Multi criteria decision making methods based on intuitionistic fuzzy sets. European Journal of Operational Research, 179, 220233.

Nie, R.X., Wang, J.Q., Zhang, H.Y., 2017. Solving solarwind power station location problem using an extended weighted aggregated sum product assessment (WASPAS) technique with interval neutrosophic sets. Symmetry, 9(7), 106.

Özbek,A .and Erol,E., 2016. COPRAS ve MOORA yöntemlerinin depo yeri seçim problemine uygulanması. Ekonomi, işletme, siyaset ve Uluslararası ilişkiler Dergisi, 2(1), 23-42.

Sağnak,M.,2020. Depo yeri seçimi : perakende sektöründe melez çok kriterli karar verme uygulaması. Journal of Yaşar University, 15(59), 615-623.

Singh R.K., Gunasekaran A. and Kumar, P., 2018. Third party logistics (3PL) selection for cold chain management: a fuzzy AHP and fuzzy TOPSIS approach. Annals of Operations Research, 267, 531553.

Tayalı, H.A., 2017. Tedarikçi seçiminde WASPAS yöntemi (WASPAS method for supplier selection). Asos Journal, The Journal of Academic Social Science, 5(47), $368-380$

Turskis, Z., Zavadskas, E.K., Antucheviciene, J., Kosareva, N., 2015. A hybrid model based on fuzzy AHP and fuzzy WASPAS for construction site selection. International Journal of Computers Communications \& Control, 10(6), 113-128.

Xu,Z.S. and Yager,R.R.,2006. Some geometric aggregation operators based on intituitionistic fuzzy sets. International Journal of General Systems, 35, 417-433.
Yıldırım, B.F and Meydan, C. 2021. Sezgisel Bulanık Edas (SB-EDAS) yöntemi ile finansal performans değerlendirme : BIST perakende ticaret sektöründe bir uygulama. Süleyman Demirel Üniversitesi Vizyoner Dergisi, 12(29), 235-251.

Zadeh,L.A.,1965. Fuzzy sets. Information And Control, 8(3), 338-353.

Zavadskas,E.K., Turskis,Z.,Antucheviciene,J. and Zakarevicius, A., 2012. Optimization of weighted aggregated sum product assessment. Elektronika ir elektrotechnika, 122(6), 3-6. 